\title{
Track Two Diplomacy from a Track One Perspective: Comparing the Perceptions of Turkish and American Diplomats
}

\author{
C. Esra Çuhadar Gürkaynak* \\ Department of Political Science, Bilkent University, Bilkent Ankara 06800, Turkey \\ email: esracg@bilkent.edu.tr
}

Received 29 January 2006; accepted 3 May 2006

\begin{abstract}
Although it is often implicitly assumed by track two practitioners that track two efforts are complementary to official negotiations and are welcomed by official actors, little is known about the actual perceptions of these efforts by official parties, especially in the context of non-Western countries. Turkey, as one of these countries, was exposed to numerous track two efforts in the last decade. A survey of Turkish diplomats was conducted to explore how interventions by American- and European-based track two actors are perceived by the track one community in a developing and non-Western country. The Turkish diplomats' perceptions are organized around four categories: who are the track two actors, contributions of track two diplomacy, problems caused by track two diplomacy, and ideas concerning track two-track one cooperation. Then, the perceptions of Turkish and American diplomats are compared to assess whether their perceptions of track two diplomacy differ and, if so, in what particular ways they differ. The theoretical and practical implications of the findings are discussed and ideas for future research proposed.
\end{abstract}

Keywords

cooperation between track one and track two diplomacy, complementarity, Turkish diplomats

\section{Introduction}

Unofficial encounters among representatives of groups that are in conflict with each other (known as track two diplomacy) in the hope of affecting official negotiations (known as track one diplomacy) have been carried out with increasing frequency over the last two decades. It is often implicitly assumed by track two practitioners that track two efforts are complementary to official negotiations and that they are welcomed by official actors. Little is known, however, about the actual perceptions of the official parties concerning these efforts, especially in the context of non-Western countries. This study tries to remedy this deficiency by presenting evidence from a survey of Turkish diplomats on their views of track two efforts and comparing these to a similar survey of American diplomats.

\footnotetext{
*) Esra Çuhadar Gürkaynak is an Assistant Professor in the Political Science Department of Bilkent University. 
Track two diplomacy has increasingly been recognized as an innovative means of third party intervention in international and intra-national conflicts. This term, 'track two diplomacy,' was first coined by Joseph Montville as referring to "unofficial, informal interaction between members of adversary groups or nations that aims to develop strategies, influence public opinion, and organize human and material resources in ways that might help resolve their conflict" (1987: 7). Other terms were also used by various scholars, i.e. multi-track diplomacy (Diamond and McDonald 1996); unofficial diplomacy (Volkan et al. 1991); sustained dialogue (Saunders 1999); and interactive conflict resolution (Fisher 1997) to refer to similar conflict resolution activities - activities that are often facilitated by a third party and are of an unofficial and interactive nature. In this article, the term 'track two diplomacy' is used interchangeably with 'unofficial diplomacy.' It refers to a variety of non-governmental and unofficial forms of conflict resolution activities between the representatives of adversarial groups that aim to de-escalate conflict, improve communication and understanding between the parties, and develop innovative ideas to be used in 'track one.' The term 'track one,' or 'official diplomacy,' is used to refer to peacemaking activities conducted by officially appointed people (e.g. diplomats), governmental agencies (e.g. diplomatic and defense organizations), and inter-governmental organizations (e.g. UN or NATO).

Recently, there are signs of growing interest and recognition among track one actors towards track two actors and their activities. ${ }^{1}$ At the same time, an effort to reach out to the track one community is visible in the track two community. The necessity of relating and contributing to track one have always been articulated, theoretically, as an important goal by various track two scholars and practitioners. Volkan (1991: 12), for example, emphasized the importance of the 'crucial juncture,' referring to a state in which official and unofficial diplomacy interacts with one another and searches for ways to improve this interaction. Other scholarpractitioners, such as Fisher (1997), Kelman (1995), and Mitchell (1993) discussed conditions - especially pertaining to the selection of workshop participants - under which the successful 'transfer' ${ }^{2}$ of ideas from track two workshops to the policymaking level can be realized. In a recent attempt to further elaborate transfer, a collection of articles by Fitzduff and Church (2004) discussed cases and strategies through which NGOs managed to influence policy processes in peace related issues in different parts of the world. They differentiate between two types of strategies that NGOs use to influence policymaking processes around the globe: 'insider strategies,' which refer to working alongside the policymaking circles; and

\footnotetext{
1) As examples for growing interest towards track two actors, see for example "Secretary's Open Forum" organized by the Department of State in 2002, and the "Track One-Track Two Symposium" organized with the sponsorship of the United States Institute of Peace on 24 November 2003.

2) For a detailed discussion of this concept see Cuhadar (2004) and Fisher (1997).
} 
'outsider strategies,' which refer to working with people outside the decisionmaking circles and placing external pressure. They finally argue that different cases call for different combinations of these approaches.

Besides the scholarly work on how track two can relate to and influence track one, there is a growing literature on complementarity and coordination of track one and track two activities (Crocker et al. 1999, Kriesberg 1996, Nan 2000). In addition to this growing scholarly literature, recently members of both communities have sought forums to find out how to put these ideas into practice more effectively. ${ }^{3}$ The fact that more frequent interactions take place between the members of track two and track one communities in these forums is a positive step towards establishing dialogue and identifying ways to make peacemaking efforts more complementary and coordinated. However, the increasing level of interactions also raises further issues that need to be analyzed and tackled.

While track one and track two communities communicate with each other to increase complementarity and coordination, their interaction is often influenced by their perceptions towards each other, which are shaped by past experiences, norms and values of the professional culture they belong to, and national differences. These differences can potentially constitute a barrier to effective communication and coordination between the two communities. The barriers may be highlighted even more when the interlocutors of the US or European based track two practitioners are mostly track one communities of developing and 'non-Western' countries. ${ }^{4}$ Furthermore, despite the fact that most of the track two practice is carried out in countries other than the US and Europe, attempts to understand the views of track one communities in these countries and to involve them in the recently flourishing track one-track two dialogue are inadequate. Although track two diplomacy is carried out in many different parts of the world with very different cultural groups (official and unofficial), the topic has hardly been studied cross-culturally. Practitioners such as McDonald (1991: 216) have neither adequately addressed this gap nor have raised concerns related to the implications of applying track two diplomacy across different cultures. McDonald advised unofficial American diplomats to acquire patience, humility, and a detailed knowledge of the issue and the area before entering negotiations. Although such advice is very valuable for unofficial diplomats, especially on a practical level, there is still need for a more analytical effort to understand the dynamics of track one-track two relationship in 'non-Western' countries.

\footnotetext{
3) See endnote 1.

4) Most of the international track two practitioners are based in the developed world such as the US or Europe. Indeed, the theory and practice of track two was initiated in these countries. However, most of the conflicts they deal with exist in developing countries in other parts of the world. Here I use the terms 'Western' and 'non-Western' as general categories to refer to this specific distinction. The term 'non-Western' does not necessarily mean that the country is not modernized nor has no elements of Western culture in it. A good example to this would be Turkey where the modernization process has been going on for more than a century and where one can easily find many basic elements of the Western culture.
} 
In light of this void, this article offers a survey of Turkish diplomats to explore two questions. The first is how outside intervention by US and European-based track two actors is perceived by the track one community of a developing, non-Western country, which often lies at the receiving end rather than the service-providing end of this relationship. The second question, related to the first, is whether the perceptions of Turkish and US diplomats towards track two diplomacy differ and, if so, in what particular ways.

The research that answers these questions is presented in four parts. The first part discusses the rationale of carrying out this research in Turkey and the methodology. The second part presents the research findings with regard to the perception of Turkish diplomats towards track two efforts in four categories: a) who the 'legitimate' actors of track two diplomacy are, b) the contributions of track two diplomacy, c) harms caused by track two diplomacy, and d) ideas concerning track two-track one cooperation. The third section compares the findings from the survey of Turkish diplomats with the findings from a group of American diplomats 5 . Finally, the last section of the article discusses the theoretical and practical implications, focusing on whether there are any measures that the track two actors can take in order to improve cooperation with track one actors of the 'receiver' and 'non-Western' countries.

\section{Rationale and Conduct of the Research}

Chataway's survey $(1998,1999)$ of American diplomats was the first systematic and scholarly analysis of the perceptions and attitudes of track one diplomats towards track two diplomacy. The findings of her research offer important insights that can form the basis of a comparative analysis with diplomats in a different social and political context. My research with the Turkish diplomats was designed with the purpose of such a comparison in mind.

In January and February 1999, 27 in-depth interviews were conducted with diplomats at the Turkish Ministry of Foreign Affairs, with some follow-up interviews conducted later in the summer of $2000 .^{6}$ The group included 6 women and 21 men, all of whom had at least 10 years of diplomatic experience. The interviews aimed to understand the attitudes of Turkish diplomats towards track two diplomacy, especially how they perceive 'outside' intervention by North American and Western European unofficial actors. In order to make the comparison with American diplomats more focused and structured, the interview questions

\footnotetext{
5) This research was highly inspired by a similar survey, conducted by Cynthia Chataway, among a group of American diplomats. However, for the comparative section in this paper, the data on American diplomats were obtained from the publication of the research findings in Cynthia Chataway, "Track II Diplomacy from a Track I Perspective," Negotiation Journal, July 1998, pp 269-286, rather than from the original data set used by the author.

6) Chataway also used a sample of same size.
} 
were similar to those used by Chataway and the sample for the interviews was also formed similarly to hers. ${ }^{7}$ A group of Turkish diplomats more knowledgeable about track two processes were selected and contacted. The rest of the diplomats were selected randomly by snowball sampling. Interviews were conducted in Turkish; they were transcribed and translated into English and coded using the same general themes used by Chataway in her coding. ${ }^{8}$ However, some new themes emerged in the Turkish sample that did not exist in the American sample, which I will discuss in detail in the next two sections. Themes are reported based on their frequency, which is narrated in general terms as 'all-many-most' (which indicates the most frequent theme mentioned by more than half of the group), 'some' (which indicates the middle point on a general scale between many and few), and 'few' (which indicates the least frequently mentioned themes).

The reason Turkey was selected for this project is that, when this research was underway, Turkey was afflicted by many conflicts (some violent) both nationally and regionally, such as the Kurdish conflict, the Cypriot conflict, and the turmoil in the Balkans and the Middle East. Turkey was the subject of numerous unofficial interventions pertaining to these conflicts in the last couple of decades that were carried out either solely by the US or European based organizations and practitioners or by these 'outsiders' in collaboration with local NGOs and practitioners. The intensive exposure of the Turkish diplomats to unofficial actors in the last decade made this country an interesting case for the analysis of track one-track two interaction in a periphery country context. As mentioned before, track two theory and practice first emerged in the US and Western Europe, where civil society is more developed and the financial resources for such activities are abundant. As opposed to the US or some European countries that can be seen as 'core countries' or 'global service providers' of track two efforts, Turkey can be seen as a 'periphery country' or located at the 'receiving' end. ' Therefore, diplomats of countries such as Turkey experienced track two activities more passively, either as observers of these efforts organized by foreign actors or as targets of such 'outside' interventions. Given this context, this research has been based on the assumption that the perception of track two diplomacy by track one diplomats in Turkey is likely to differ from those in the US or Europe, where the idea and practice was initiated but seldom applied to conflicts of their own.

\footnotetext{
7) Chataway first interviewed eight diplomats who were very knowledgeable about track two processes. Out of the 26 interviewees, she selected the rest of the diplomats randomly. See Chataway 1998, p. 271 for the details of her research methodology. Also see Ibid. p.286 for the interview questions used by the author.

8) Chataway coded the interviews for: 1) definitions and distinctions made between unofficial and official diplomacy; 2) perceived contributions and dangers of track two; 3) future projections regarding the uses and abuses of track two.

9) I would like to thank the anonymous referee for suggesting the terms 'global service provider' and 'receiver.'
} 


\section{Perceptions of Turkish Diplomats}

\section{Who are the 'Legitimate' Actors of Track Two Diplomacy?}

With regard to their perception of potential and legitimate track two actors, diplomats can be divided into two groups: those who defined the track two actors broadly and those who defined them narrowly. Diplomats who defined the track two actors in a broad way recognized a wide range of actors as potential and legitimate track two actors. Most of them considered NGOs, civil society organizations, businessmen, citizens, media, independent research institutions, and conflict resolution professionals as potential actors. Diplomats who viewed the actors of track two diplomacy from a broader perspective also recognized that track one has changed to a great extent, in the sense that official diplomacy alone is not sufficient anymore in tackling contemporary international conflicts. Those who chose to state a reason for the insufficiency of official diplomacy mentioned the increasing specialization, complexity, and interdependence in international issues, the need to deal with the contemporary issues in a multidimensional way, and the global trend towards democratization. One of the diplomats who shared these thoughts put it in the following words:

\footnotetext{
Today, diplomacy is evolving away from power-based issues towards humanitarian issues. The diplomats of today, unlike their colleagues 50 years ago, have to deal with issues such as the situation of the prisons, humanitarian aid, torture, environment, and women's rights.
}

A smaller group of diplomats defined the actors of track two diplomacy in a narrower manner, as constituted of only research institutions, businesspeople, or experts and unofficial people appointed by track one to support the negotiations following a framework agreement. For instance, one such diplomat categorized the legitimate actors of unofficial diplomacy as "those who were once diplomats engaging in unofficial activities and those who never held a diplomatic position, but still can engage in diplomatic activities such as businesspeople." In this smaller second group, there was a tendency to limit track two diplomacy with either 'off the record' efforts outside of the official framework, undertaken by official and quasi-official people, or with the activities of certain types of actors only. Of these actors, the role of businesspeople was particularly and frequently mentioned, especially in reference to the "relative ease of getting business people together despite political problems." Such diplomats, who have a functionalist perspective on track two, see economic interests as an essential motivating force for political cooperation. In line with this view, businesspeople were also mentioned for their ability to influence political circles. 


\section{The Interaction between Official and Unofficial Diplomacy}

Each interviewee made a unique contribution to the research with the different perspectives they provided on unofficial diplomacy. In general, however, the general attitudes of the interviewees can be grouped into three thematic categories: supportive, selective and suspicious. Diplomats in each category tended to think similarly about the legitimacy and contributions of unofficial diplomacy, harms that may be caused by track two diplomacy, and complementarity and coordination between track one and track two actors. These groupings should be thought of as a continuum. At one extreme of this continuum are those who viewed track two diplomacy as a useful activity and as something that should be encouraged, regardless of conditions. This will be called the supportive attitude. Diplomats in the supportive group were the ones who usually had positive experiences with track two actors. The other extreme is the suspicious attitude, which included diplomats who saw unofficial diplomacy as useless and potentially dangerous in most cases. Finally, the opinions that fall into the middle of the continuum constitute the selective attitude. This group includes those who thought that unofficial diplomacy was useful depending upon the actor, issue, and timing. Such diplomats often had a chance to examine or experience track two in more than one setting. Table 1 indicates the distribution of Turkish diplomats into these categories. The following discussion will therefore be organized based on these general attitude groups.

Table 1: Distribution of Turkish diplomats according to their general attitudes towards track two

\begin{tabular}{lccc}
\hline & Supportive & Selective & Suspicious \\
\hline Distribution & 9 & 10 & 8 \\
Perspective & Useful & $\begin{array}{c}\text { Useful depending on } \\
\text { timing, actor, and issue }\end{array}$ & $\begin{array}{c}\text { Hardly useful, more } \\
\text { harmful than useful }\end{array}$ \\
Desired Role & Major or Crucial & Subsidiary & None \\
\hline
\end{tabular}

\section{Contributions of unofficial diplomacy}

This section presents the diplomats' views on the contributions of track two diplomacy. Diplomats in the supportive and selective categories believed unofficial diplomacy to be either always or sometimes useful, respectively. One of the most frequently mentioned ideas by the diplomats in these two groups was the inflexible nature of track one due to official 'record' concerns and the 'official hat' diplomats have to wear. Many diplomats in these groups emphasized that the flexible and creative atmosphere created by track two actors is conducive to generate new 
ideas that may facilitate the resolution of certain conflicts. Some of them also mentioned that official diplomacy does not leave room to address the psychological aspects of conflicts, which is a shortcoming in developing new approaches to deep-rooted historical problems. Most of the diplomats in these categories stated that they saw dialogue attempts towards the disclosure or elimination of cultural and psychological barriers such as bias, distrust, and prejudice as useful, because they can help each side to build empathy and to understand each other's perspective.

Diplomats in the supportive group stated that track one, while formulating or evaluating its policies, often benefits from the ideas generated at these unofficial meetings, because information garnered from multiple sources relevant to a conflict leads to better policies. A couple of diplomats gave the example of psychological barriers to Turkey's integration with the European Union and how track one alone remains insufficient to address the historical bias and prejudice against the Turks in Europe. They also mentioned the usefulness of track two efforts with Greece. However, some diplomats added that these dialogue efforts should be 'realistic' rather than like 'romantic love duets,' which illustrated their concern that dialogue without a clearly defined goal or task may not be useful at all. Additionally, some diplomats in the supportive group believed that such efforts should not only concentrate on people and problem-solving workshops, but also on the education system and the media. In order to further illustrate this point, these diplomats continuously referred to the negative impact of derogatory expressions in Greek textbooks and in the Greek and Turkish media. Some of them mentioned that methods other than problem-solving workshops, such as student exchange and tourism, could also be incorporated into the repertoire of track two actors. As one diplomat stated: "there are different methods to make one say this new piece of information is different from what I was told before."

Many diplomats in both the supportive and selective groups referred to the communicative contributions of track two diplomacy, especially when communication between countries is stuck or inadequate. From their perspective, such activities not only leave channels open, but also prevent the ossification of a problem. In this regard, many diplomats mentioned the face saving characteristic of track two diplomacy, especially when track one wants to maintain communication or start negotiations, but is reluctant to do so because of possible reactions at the domestic level.

Another contribution that is frequently mentioned by many diplomats in the supportive category is the reliability and confidentiality of unofficial actors while conveying a message. These diplomats pointed out that no matter how correct the information given by official diplomacy is, it may be perceived as state propaganda as long as it is uttered by an official mouth. On the other hand, some of the unofficial actors, whose impartiality and independence are trusted by the conflicting parties, are often perceived as more reliable by the stakeholders in a conflict. 
Most of the diplomats in the supportive category also mentioned the need to achieve peace at every level of society through the implementation of a multi-level peace process. Such diplomats argued that states cannot reach every level within a society and that today's inter-communal conflicts require peacemaking efforts to take place at all levels. This can only be achieved with the contributions of unofficial actors at the grassroots level. Some of the diplomats also referred to the importance of communication with interest groups in a particular country through unofficial actors.

Still another frequently mentioned benefit of unofficial diplomacy by supportive and selective groups was its contribution to the strengthening of democratic participation and to raising the public's social and political awareness of international issues. One diplomat stated that the participation of a group of Turkish women in an international women's dialogue effort concerning the violations of women's rights in Afghanistan would give a clear message to the Turkish government that these women did not find the Turkish policy on this issue adequate. Another diplomat in the supportive group stated that he believed it is very beneficial for the public to take initiative and reclaim some control over their future by participating in international affairs. Still another argued that unofficial diplomacy helps official diplomacy to maintain its transparency, openness, and democratic form. Indeed, most of the diplomats in the supportive category stated that unofficial activities can bring especially positive results to bear in democratic societies, where track one is more receptive to public opinion. Following the statements of the diplomats in the supportive group, it can be argued that these diplomats' views on the intentions and goals of track two diplomacy are parallel to the goals of track two diplomacy as articulated by the unofficial practitioners themselves.

Diplomats in the second category, who have a more selective approach towards track two diplomacy, shared most of the supportive group's ideas about why and in which areas track two diplomacy is useful, such as in opening channels of communication when the official channels are stuck and in offering alternative solutions to conflicts. However, there are still differences between their general attitudes towards track two diplomacy. Unlike the supportive group, diplomats in the selective group expressed their approval of the contributions of track two diplomacy only under certain conditions. Therefore, according to these diplomats, track one can benefit only from the activities of 'certain' unofficial actors, at 'certain' times, and on 'certain' issues.

With regard to actors, many diplomats in the selective group suggested that only certain unofficial actors, i.e. businesspeople, are useful. Such people emphasized that businesspeople are especially beneficial because they are equipped with political influence and they have economic motivations that can move the conflicts beyond political deadlock. Another frequently mentioned condition about the characteristics of actors was a preference for local and regional actors instead 
of 'foreign' ones, as well as actors that are 'impartial and unbiased.' Most of the diplomats in the selective group suggested that if there were to be a 'foreign' unofficial third party, it must prove its reliability and objectivity towards both of the parties in the conflict before intervening. Some of them also stated that local or regional actors are more useful, because they know the conflict and culture better. These diplomats listed 'good will,' 'good intentions,' and 'constructive methods' as requirements of track two actors for them to be regarded as beneficial. Some diplomats in this group also mentioned that unofficial diplomacy could only be useful if the track two actor had goals compatible with those of the official diplomacy. On the other hand, diplomats in the supportive group did not see compatibility between the goals of track one and track two as a prerequisite for receiving the benefits. Unlike the selective group, these diplomats even stated that multiple voices, disagreements, and incompatibilities were indicators of a wellfunctioning system.

On the topics of selected issues and timing, the selective group thought that track two diplomacy would be more useful when: a) track two processes work parallel to the signing of a political agreement or afterwards during the peace building stage in order to improve relations at the community level, b) track two is carried out parallel to cooperation signals from track one, or c) if there is no violent political conflict. Diplomats who emphasized the first two conditions believed that without an overarching political framework, or at least a political willingness to cooperate between the parties, track two processes would be fruitless. Those diplomats who referred to the contributions of track two after a political agreement is signed addressed the need for post-conflict rehabilitation and community building, especially in reference to the Bosnian example. Therefore, selective diplomats not only identified conditions pertaining to specific actors, but also conditions pertaining to the timing of track two interventions.

Another major difference between the supportive and selective groups was that, unlike the diplomats in the supportive group who assumed that unofficial activities somehow influence the policy level, diplomats in the latter group expressed more pessimism and hesitation about the ability of track two to influence official policymaking. They were also more skeptical about the interpersonal consequences of the problem-solving workshops and dialogue groups. Unlike the diplomats in the supportive group who thought that interpersonal relations matter in foreign policy,' diplomats in the selective group emphasized the systemic and structural barriers as obstacles to peace and expressed doubts about the potential impact of improved interpersonal relations in challenging these structural barriers. The selective group diplomats also expressed concerns about the 're-entry problem ${ }^{10}$ that is frequently experienced after the problem-solving workshops. Related to the re-

\footnotetext{
10) Re-entry problem refers to the difficulties the track two participants face when they go back to their societies after going through a series of meetings and changes in an isolated environment.
} 
entry problem, these diplomats argued that as long as governments and educational systems keep fueling adversarial attitudes, social-psychological barriers cannot be eliminated solely through problem-solving workshops. Some of these diplomats gave as an example for failure the unofficial efforts concerning the GreekTurkish relations. They expressed doubts about these efforts, stating that track two actors had been trying these methods for 20 years between Greeks and Turks in Cyprus without any significant results.

Finally, as far as the attitude of the suspicious group is concerned, diplomats in this group hardly believe in any contribution of track two diplomacy and view track two actors with suspicion regardless of the actor, timing, and issue. This attitude is significantly different from the previous two groups. Although some reservations were stated by diplomats in the supportive and selective groups as well, especially with regard to the reliability of some unofficial actors, these related only to a few, specific issues.

One significant point that was frequently mentioned by all diplomats in the suspicious group was that unofficial actors were manipulated by certain power groups, and especially by certain states, to serve their interests and purposes. They believed that some states use unofficial actors to manipulate and shape the conflict in their favor and to impose the solution they desire. Diplomats in this group also accused track two actors for being biased, having double standards, and being used as propaganda tools. They viewed their activities as distorting and misleading. A few diplomats mentioned that it is hard to believe in the sincerity of most of the NGOs, because while they react against an issue in one country and start a campaign against it in the international arena, they simply ignore similar practices in other countries. Almost all the diplomats in this group expressed doubts about the financial sources of track two activities and actors. They said that most of the time the aims of the financial sponsors are not transparent and that they disguise their political affiliations and goals with the help of unofficial actors. One diplomat added that such NGOs deliberately select only people who can easily be manipulated, or who are already opponents of the regime, to participate in their problem-solving workshops. Therefore, the outcomes of these workshops are portrayed as though it was the general tendency of the entire society in an attempt to manipulate the issue and the political efforts. The same diplomat mentioned that the workshops that focus on 50-100 people in total could not be regarded as legitimate due to their limited size and representation. Some diplomats in this group asserted that these workshops are like 'platonic love affairs' and that they are unsubstantiated.

Diplomats in this group exhibited suspicion toward the methods and philosophy of conflict resolution in general and towards problem-solving workshops in particular. Many diplomats in this group made the point that the problem-solving workshops that bring unofficial people together are not useful as a method, because conflicts do not occur between individuals within societies, but simply between 
competing national interests. Plus, conflicts that arise from history or culture could not be overcome by outside intervention or by problem-solving workshops that are limited in scope. One diplomat stated that Western conflict resolution experts, or think tanks and research organizations, often assess conflicts in 'laboratory conditions' and then they try to implement these sterile ideas to a 'real' situation that most of the time differs drastically from what is simulated in 'laboratories.' Another diplomat stated that there are cultural and historical biases towards Turkey in Europe that are continuously perpetuated by the media and are always reflected in the activities of the unofficial channels in this region. Therefore, these channels are far from impartial and sincere in their efforts. In sum, the views expressed by the suspicious group suggest that track two diplomacy is hardly perceived as legitimate and its contributions are not fully recognized.

\section{Perception of Harm}

It has already been noted that diplomats in the suspicious group view track two not as useful, but instead as rather harmful. Besides this suspicious attitude, diplomats in the supportive and selective groups also mentioned specific situations where track two diplomacy could be harmful. Although the perception of harms among the supportive and selective categories converged on many points, the former distinguished itself from the latter with respect to the methods in dealing with these situations. This subsection will discuss the perceptions of supportive and selective groups with regard to harms.

Many diplomats mentioned that if the unofficial actor has a "narrow and one-sided approach," either based on prejudice or inadequate information about the context of the conflict, it can be harmful. Another frequently mentioned potential harm was related to the possibility of the manipulation of the organization or the person participating in track two activities. In line with this argument, several diplomats said that if there are personal benefits involved in the track two effort, such as profit or propaganda, the consequence of such an effort might be harmful.

A third frequently mentioned potential harm, especially by the diplomats in the selective category, was that if unofficial diplomacy "overwhelms" official diplomacy, it may cause problems. By "overwhelming," some diplomats meant the disclosure of track one secrets in unofficial meetings, while others meant creating "undue expectations" for the other party or signaling "rosy messages" when the official negotiation position is less flexible. For this reason, some of the diplomats suggested that the boundaries of unofficial diplomacy need to be drawn more clearly. Otherwise, false expectations may be created on the other side, which in turn might contribute to the further escalation of the conflict and to the hampering of the efforts of track one. These diplomats mentioned that in case of such damage, it is very difficult to fix the problem or reverse the damage. As a solution, 
some diplomats suggested that track two diplomacy needs to be realistic, responsible for the consequences of its actions, and it needs to be sensitive and familiar with the interests of all parties in the conflict. Others bolstered this idea by stating that track two diplomacy should be careful "not to transcend its area of expertise."

Another point mentioned by some diplomats, especially in the selective category, concerned the harms caused by the ideological stance of some unofficial actors. For instance, such diplomats saw unofficial diplomacy as potentially harmful, if the actor is a radical Islamist or an advocate of a particular ethnic group. They think that such unofficial actors try to distort the issue and mobilize people around their specific cause, rather than searching for a resolution to the dispute or aiming at problem-solving and reconciliation. They added that such actors can also damage the "image" of official diplomacy and the country they represent. Concern with the "image" of the country was mentioned quite a few times by different diplomats in various contexts. "Damaging the image of the country" was perceived to be one of the most important harms, which indicates the notion that track two diplomacy can potentially become a "meddler" with the representation mission of official diplomacy. In other words, these diplomats see track two diplomacy as potentially harmful, if the latter intends to represent the country in a way not approved by official diplomacy. This issue is of critical importance for the Turkish diplomats, given that the "representation" of the "modern and secular Republic" is one of the pillars of official Turkish diplomacy.

A significant number of diplomats pointed to the harms caused by 'biased' and 'hypocritical' activities of some unofficial actors, those of NGOs in particular. Although this point was stated before as one of the primary concerns of the suspicious group, unlike this group, diplomats in other categories did not think that unofficial channels were not useful at all because "some of them are manipulated and used by some states for the defamation of a particular country." The response of the diplomats in general was that harms caused by "intentional defamation" are very difficult to erase once world public opinion is formed as a result of such manipulation. One diplomat added that: "the only thing you can do [at that point] is to find out the reasons for the [destructive defamation] behavior." Another diplomat with the selective attitude suggested "to try to convince [such actors] to change their destructive behaviors through dialogue, and if this doesn't work, take legal action if possible and appropriate."

Concerning the harms caused by track two actors, a few diplomats in the selective group addressed the harms caused by "foreign unofficial actors." The reason mentioned was that they was not necessarily familiar with the "real issue," especially the "complexity of the conflicts in a particular region of the world." These diplomats suggested that such actors should be more familiar with the issues and culture of the region.

In sum, it can be argued that most of the harms mentioned by the diplomats in the supportive and selective groups are related to the characteristics of the 'actors' 
of track two diplomacy rather than the nature of the track two activity itself. This is clearly seen in the arguments raised concerning issues such as bias, prejudice, and lack of adequate knowledge and skills in track two actors.

As far as how these harms or potential harms can be avoided or eliminated, most of the diplomats in the supportive category offered a 'self-control' or a 'checks and balances' mechanism. They also pointed to the fact that this is the area where Turkey is facing difficulties with track two diplomacy, because these mechanisms are not working efficiently enough. Again suggested by some diplomats in this category was the need for transparency, both in official and unofficial diplomacy, and a mechanism that would help people to know "who is who" in track two diplomacy. Another frequently suggested method was to increase the "exchange of ideas" and "to keep contact between the two channels." Some of the diplomats also referred to the need for more "responsible behavior" on behalf of track two actors concerning the problem of creating "undue expectations", but did not specify any particular method.

An interesting perspective was put forward by a few diplomats in the supportive category regarding the issue of harm. These diplomats offered a relativist view on the issue through consideration of the "subjective nature of harm". One diplomat said the following:

I don't think, in open, liberal, and democratic societies, unofficial diplomacy can be harmful. If you have problems with these notions, then you begin worrying about the acts of unofficial diplomacy and say that it can be 'sometimes harmful'. If it is a totally anti-democratic and closed system, then the regime says that unofficial activities are of no use at all and they are always harmful.... In democratic societies, official diplomacy cannot say anything like this. In societies like Turkey, that are in between, and are trying to consolidate democracy, it will depend on the person, subject, and the organization. Then, official diplomacy becomes suspicious and wonders whether they will talk about one of the shortcomings of the country.

The discussion on the subjectivity of harms was further enriched with one diplomat's statement that it is inevitable that official diplomacy will consider everything that threatens its existence as harmful. Along the same lines, yet another diplomat from the supportive group mentioned that the perception of harm depends on the type of the regime and on the political culture. This diplomat continued that, rather than viewing harmful situations as "white and black", there are "tones of gray," and as long as there is "good faith and responsibility," track two diplomacy is not harmful.

As far as the methods suggested for the elimination of harms are concerned, most of the diplomats in the selective group suggested contact, dialogue, or at least 'information exchange' between track two and track one actors, so that the latter can inform the former about potential problems. On the other hand, most of the diplomats in the supportive category suggested that track two actors need at least to be aware of the activities of track one in that area, regardless of whether or not they agree with its policy. 
In sum, a major distinction between the selective and supportive groups emerged with regard to the elimination of harms. While the selective group preferred a more controlling approach towards track two, the supportive group was consciously more reluctant to portray this type of attitude.

\section{Coordination Between Official and Unofficial Actors}

Identifying the situations in which track two and track one can work in complementary and coordinated ways is a major challenge for the scholars and practitioners interested in track two diplomacy. Scholars such as Crocker, et al. (1999), Cuhadar (2004), Keashly and Fisher (1996), Kriesberg (1996), and Nan (2000) addressed this challenge in different ways, but at the end, all concurred that the complementary use of various third party methods increases the effectiveness of overall peace efforts. Of these scholars, Keashly and Fisher (1996) and Nan (2000) dealt with the question of complementarity and coordination within a "contingency approach" framework. The contingency approach suggested that the type of third party intervention (e.g. negotiation, mediation, consultation, arbitration/power mediation, development aid) should match the characteristics of the conflict and what is needed at that particular conflict stage (e.g. discussion, polarization, segregation, destruction) (Keashly and Fisher 1996: 245). In this framework, Keashly and Fisher (1996: 257) advocated a "coordinated sequenced approach" in which they discouraged "over-reliance" on one particular third party intervention method and encouraged a "healthy eclecticism" of various methods. However, they argued that consultation/facilitation, which can be carried out by unofficial actors and aims at improving relationships and communication between the parties, is relevant and complementary to other third party methods in almost all stages of a conflict, albeit in differing intervention sequences. Following in their footsteps, $\operatorname{Nan}$ (2000: 332) found that "long-term unofficial facilitated joint analysis" in between negotiations is highly complementary to official negotiations. By long-term unofficial facilitated joint analysis, Nan referred to the unofficial activities undertaken by a small number of third parties with high level representatives over a long time period.

In addition to these scholars, Kriesberg (1996) suggested two types of coordination that can take place between various peacemaking actors according to the timing of the intermediary efforts, "sequential" and "contemporaneous". While sequential efforts refer to the third party activities that follow one another, contemporaneous efforts refer to the simultaneous activities of more than one third party.

Although these studies do not necessarily deal with track one and track two relationship per se, they have contributed to our understanding of situations under which track one and track two can work in complementary ways and when coordination between the two is necessary. However, research and theory building in this area is still at an early stage. One issue that requires further inquiry is to 
understand the intentions and perceptions of track one towards coordination with track two. Do they think coordination is necessary? What motivates them to think that they need coordination? In what areas do they think coordination with track two is more relevant? Understanding track one's perspectives concerning these questions will help us think about track one and track two coordination in a way that involves the interests of both stakeholders in this area.

As in the previous sections, views of diplomats towards coordination vary with the suspicious, selective, and supportive attitude groups. For the suspicious, since unofficial actors are viewed as not useful, but rather harmful, it is very difficult to talk about the means of coordination with this group. The major barrier to coordination with such diplomats is track two's lack of legitimacy. However, it is still very important to understand the reason why track two is not seen as legitimate, because different reasons may require different strategies for track two practitioners.

For some diplomats in this group, the suspicious attitude towards track two is consistent with the views they expressed about civil society and NGOs in general as having been "formed against the state, they will not want to cooperate with the state." Such thinking may be due to their lack of knowledge about, and limited experience with, civil society, and may be due to the political culture in which the relationship between the state and civil society has evolved differently from the one in Western European societies. ${ }^{11}$ For example, the concept of the NGO did not exist until the 1990s, whereas the more traditional term vakif (waqf) was used to designate civil society organizations, however, these were not completely independent of the state realm, especially in modern times. ${ }^{12}$ For diplomats with such a worldview, it is harder for track two to change this perception and eliminate the source of non-recognition and thus, coordination or any cooperative work between such track one actors and track two may simply not be feasible.

On the other hand, for the majority of diplomats in the suspicious group, track two is not seen as legitimate, because track two activities are not capable of finding solutions to the 'essence' of the problems, but rather offer palliative solutions and are manipulated, non-transparent, and used by certain powers to impose their own solutions in a conflict. For suspicious diplomats who state this as the reason for non-recognition, coordination may be relatively easier. For coordination or cooperative work to happen with such diplomats, trust building, improving the transparency and accountability of the NGOs, and mutual recognition of the importance of each other's work will likely help the situation. In addition, track two actors need to clarify and communicate their intentions and funding sources, and assure the diplomats of their impartiality in order to prevent situations in

\footnotetext{
11) For an example of scholarly discussion on how state-civil society relations in the Ottoman Empire and Turkey evolved, see Bernard Lewis 2002, chapter 5; and especially Serif Mardin, 1995.

12) For further information on the waqfs as civil society institutions in Islamic societies, see Lewis Ibid. pp, $110-111$.
} 
which the track two effort is perceived as something imposed by a "foreign state." If that is the case, coordination between diplomats of the country subject to track two intervention and the 'foreign intervener' is difficult to establish, especially in countries like Turkey, where a painful history of foreign intervention by 'Western powers' still constitutes a lively part of the collective memory. ${ }^{13}$

For diplomats in the selective and supportive groups, views on coordination vary. There are many crosscutting arguments mentioned by diplomats in both groups. However, diplomats in the selective group tend to favor coordination in sequential efforts over contemporaneous ones, as opposed to diplomats in the supportive group, who tend to recognize the value of coordination both in sequential and contemporaneous interaction between track one and track two.

A primary reason for the selective group's preference for the sequential mode is the belief that track two actors can hamper the efforts of track one if their efforts take place before a political-legal groundwork is established. Such convictions of the selective group have already been mentioned in the section on perceptions of harms in regard to the conditions put forward concerning the timing of track two intervention. Lack of coordination is harmful for most diplomats in this category and will make track two efforts "unrealistic," especially concerning "security" issues. What one diplomat said is quite representative of this attitude:

The unofficial efforts per se do not bring any results. This is a reality. They can play a supportive and catalyst role especially after a rapprochement occurs at the political level. The primary condition is the political will of the disputants. Once there is a sign of political will, unofficial channels can further improve this cooperation.

It can be contended that these diplomats prefer the coordination of sequential interaction not only because they fear "meddling" of track two diplomacy in their work (if conducted simultaneously), but also because some perceive track two to be a substitute for track one. However, although strong preference for sequential interaction between track one and track two was voiced adamantly by these diplomats, which exact sequence they preferred was not adequately clarified. Although many of them stated a strong preference for track two following the official signal of rapprochement, the other sequential option was not completely repudiated.

For some other diplomats in the selective category, another prerequisite for coordination is "professionalism" and the proven credibility of the track two actor. These diplomats think that coordination is not meaningful if the organization lacks "professional perspective on the conflict" or a "credible reputation" in the eyes of the diplomats and the public.

\footnotetext{
13) The intervention of the Western powers in the Ottoman Empire on behalf of non-Muslim minorities and later on Arab Muslims, which culminated with the occupation of the country by the Allied forces and the disintegration of the Empire is a major historical factor that underlie the skepticism of many officials concerning any Western involvement in the domestic affairs, especially on behalf of ethnic and religious communities. For a more detailed discussion, see Bernard Lewis 2002 especially chapters 2, 5, and 6.
} 
In the supportive group, diplomats are more prone to coordination in both sequential and contemporaneous efforts between the two tracks. One major difference from the previous group is that they do not see unofficial actors as potential "meddlers" if they are engaged in activities simultaneously with official diplomacy. Also, all of the diplomats in the supportive group recognized track two diplomacy as a complementary method, unlike some diplomats in the selective group who saw it as a substitute for, or as in competition to, official diplomacy. Diplomats with a supportive attitude thought that the issue of incompatibility between track one and track two is "very normal and something that needs to be accepted by official diplomacy" and an "indication of a well-functioning system in which the actors challenge one another for progress," unlike many diplomats in the selective group who thought that incompatibility between the goals of the two tracks hampers the work of track one. A diplomat from the supportive group stated:

\footnotetext{
There is a trend towards multilateralism and multi-dimensionalism. Official diplomacy is now more open and allows inputs from various channels. This is really important in avoiding situations like Yugoslavia. It is important that these channels work with each other compatibly. By compatibly, I don't mean that everybody should agree on the same thing. When you formulate principles that will regulate coordination, you should also keep in mind that there is the danger of hampering the dynamics of change. However, still, coordination is the best thing you can do to ensure that the unofficial channels make their voices heard. It is really important for different parties, groups, to hear and understand one another for better policy actions.
}

As far as the achievement and maintenance of coordination are concerned, there are various suggestions shared by diplomats in both the supportive and selective attitude groups. The bottom line is that many agree on some sort of a mechanism that will at least provide exchange of information between the two tracks. The need for information exchange was expressed by many diplomats. One stated that: "Maybe there are lots of citizens and organizations that strive for the achievement of the same goal, but either they are not aware of one another's activities or they are aware but there is lack of a mechanism that will facilitate communication and coordination between them." Most of the diplomats in the selective and supportive categories are open to input and new ideas that can be offered by unofficial actors, even if they express different uses for coordination. For some, coordination is necessary just to be able to understand the concerns and perspectives of one another, so that each side knows what to expect from the other and learn each other's position in order to avoid impairing the collective efforts. For those, "mutual dialogue" and "informatory sessions" are the preferred ways of to achieve coordination. On the other hand, for others, coordination is necessary to reevaluate and improve the current foreign policy options with the help of new ideas generated during the track two meetings. As one diplomat stated: 
Since track two diplomacy can be useful in playing a catalyst role between the track one of the parties in conflict, it should be close to both sides in order to play a bridge role. If the information obtained in the problem-solving workshops, such as why the other side fears from taking a further step, is conveyed to the decision makers, then the policymaking process can be more constructive... [Coordination] is useful because you receive more information from unofficial channels directly [so that] you can better evaluate and change your understanding of a problem.

Diplomats in the supportive and selective groups were careful to emphasize that coordination does not mean control. Most of the diplomats in these two categories indicated sensitivity in maintaining the credibility and independence of the track two actors if track one and track two efforts are coordinated. They felt the need to mention that coordination should not turn into track two becoming a "puppet" of track one. One diplomat preferred the phrase "democratic exchange of ideas" to coordination. Another expressed concern saying that "official diplomacy should not behave like an overprotective parent towards unofficial actors." Yet another one noted:

When the interests and goals of the two tracks are compatible, official diplomacy supports the efforts of unofficial diplomacy. But it is important to protect the credibility of NGOs as independent entities, because they are respected in what they say because of their independence.

In sum, as opposed to the suspicious group, coordination is well accepted and desired by the diplomats in the supportive and selective groups. For many of the diplomats in these categories, coordination is perceived as a mechanism to make peacemaking efforts more effective and to improve foreign policy options.

\section{Comparing the Perceptions of Turkish and American Diplomats}

It was noted earlier that the survey among Turkish diplomats was designed in a way to facilitate comparison with the sample of American diplomats surveyed by Chataway (1998). In this section, the findings of this comparative analysis will be discussed, with reference to both the similarities and differences between the Turkish and American diplomats regarding their views on track two efforts. This discussion results in the suggestion of ideas pertaining to the sources of these similarities and differences in order to lay the groundwork for further research in this area.

\section{Similar Perceptions}

When compared, Turkish and American diplomats expressed similar concerns and ideas about track two diplomacy using a similar language. Most of these similarities seem to be shaped by the nature of their shared professional occupation and a common diplomatic language, symbols, rituals, and behavioral patterns. One of the similarities that can be traced to the common professional 
occupation is the notion of "flexibility." The formal structure of track one and the official record problem was often mentioned by both groups of diplomats. Both Turkish and American diplomats addressed the inflexible nature of official diplomacy and indicated that track two, on the contrary, is flexible and can contribute to communication efforts. In this regard, US diplomats referred to the inflexibility of official diplomacy and indicated that official positions may constitute a barrier to free and creative communication (Chataway 1998: 275).

Another similarity related to the theme of flexibility is that both groups of diplomats referred to the contribution of track two diplomacy in reaching out to groups that official diplomacy cannot easily reach. ${ }^{14}$ Yet, another area of shared concern with regard to the inflexibility of official diplomacy is that in both groups there are diplomats who recognized the extra work burden placed on them because of the requirements of the changing international environment. Some American diplomats described the role of track two in such an environment as "out-sourcing," as a way of filling the gap created by the increased burden on official diplomacy (Chataway 1998: 272). Similarly, some Turkish diplomats addressed the inadequacy of track one in dealing with the diversification in the issues and the need for expert involvement. For both groups of diplomats, removal of the constraints on unofficial dialogue imposed by the Cold-War context and the spread of democracy resulted in the increasing involvement of citizens and thus, contributed to the development of track two diplomacy. ${ }^{15}$

For both Turkish (selective and supportive ones) and American diplomats, "the creative and informal" nature of track two is considered to be useful. As one American diplomat stated in Chataway (1998: 274): "[interactive conflict resolution] allows the testing out of new ideas and sharing information under the cover of academic discourse, without formal commitment." Similar comments were made by Turkish diplomats, such as:

$[\mathrm{O}]$ fficial diplomacy can force you to stay within certain boundaries. It has certain rigid rules and norms. It has limited communication and negotiation methods. What you can do with official diplomacy is restricted with these boundaries, ... but as an unofficial actor... you can be creative and obtain interesting information and responses.

A second theme that can be traced to the common occupational profession is found in the arguments made by the diplomats of both countries concerning national interest. Track one often embodies a discourse of 'national interest,' while track two has been built upon a 'non-violent' and 'human relations' discourse. This difference manifests itself in the statements of several interviewees. For example one Turkish diplomat argued:

\footnotetext{
14) See Chataway, 1998, p. 271 for the American diplomats' views.

15) For the American group, see Chataway, Ibid., p. 272.
} 
I don't believe in the concept of conflicts between the groups in societies. Societies do not conflict with one another. Each state has continuous national interests. [Each state] has national interests that are prioritized and the respective governments follow these national interests. Therefore, conflicts do not exist between people, but rather between these national interests.

The same discourse is expressed in the statements of some American diplomats in which they viewed unofficial diplomacy with derision regarding the issues of what they called high priority. These issues include disputes involving the United States security interests and top secret issues in which the interference of track two diplomacy is discouraged. ${ }^{16}$ Moreover, both Turkish and American diplomats expressed concerns about track two diplomacy causing "undue expectations" or "unrealistic expectations" on the other party that can damage the interests of the country or further complicate the situation. Some diplomats in both groups accused the unofficial actors as uninformed about the complexity of the issues and, thus, creating unrealistic solutions. ${ }^{17}$

A third theme that is similar is the 'representativeness and inclusiveness' of official diplomacy. It can be inferred from many diplomats' views that, while they see official diplomacy as inclusive of all interests and representative of and carrying the responsibility of the whole nation, they perceive track two diplomacy as focused and experienced in a specific issue and with limited representation, scope, and responsibility. Some Turkish diplomats argued that official diplomacy protects the interests of the whole nation whereas track two usually deals with the interests of a specific group in the society or acts in favor of a specific issue. Similarly, some American diplomats suggested that track two should not negotiate the specifics of an agreement, but instead focus on broad goals and objectives, because unlike official diplomats, they lack a broader perspective on the situation (Chataway 1998: 279). On a similar account, some Turkish diplomats said that unofficial actors such as NGOs are established based on specific causes for which they advocate in their activities, whereas, they argued, official diplomacy has to take the interests of every segment of the society into consideration. However, this was not necessarily a negative attribute placed on the unofficial actors. Several diplomats explicitly referred to this subject as a positive attribute of unofficial diplomacy, because the issue-specific focus of the unofficial actors is beneficial for official diplomacy since diplomats are no longer capable of paying attention to every issue. From these arguments, one can easily infer the contradicting views of the diplomats on the specific and issue-focused nature of unofficial actors. While one view suggests that the specific knowledge and professional experience of unofficial actors is appreciated, the other one is concerned about the overvaluation of a particular issue or interest.

\footnotetext{
16) For such comments see Ibid. pp. 274-276.

17) See p. 280 for Chataway's example on this theme.
} 
Another similarity is that some diplomats in both groups (in the Turkish case, especially some of those in the suspicious and selective groups) perceived track two actors as a threat or as a replacement of official diplomacy. These diplomats needed to reiterate that track two cannot replace diplomacy and that official diplomacy is the only venue to make final agreements. ${ }^{18}$ Both Turkish and American diplomats also raised concerns about the selfish motivations of unofficial actors. However, this was a more persistently mentioned theme among the Turkish diplomats in all categories, albeit in varying degrees, especially concerning the funding of NGOs by private interest groups. Beneath this attitude of some diplomats from both nationalities, there is a tendency to think that track one is more important and should always have the upper hand. Another revelation of this attitude can be seen in comments that suggest that track one sees its own issues as "hard core" or "high priority," and track two as dealing with issues of secondary or subsidiary importance. Such perceptions existed in some American and Turkish diplomats' (especially ones in the selective group) statements regarding the need for consistency and compatibility between the norms and goals of track one and track two. Similarly, some diplomats see unofficial activities as the extension of official diplomacy. As Chataway (1998: 274) stated:

To some interviewees citizen-diplomats were conceived as an extension of the diplomatic arm, a tool to be utilized in the service of diplomatic ends, however coercive... [Within] these statements is the sense that the norms and goals of Track II diplomacy should be consistent with those of traditional diplomacy....

Parallel views were also expressed by some Turkish diplomats in the sense that unofficial diplomacy should be compatible with and supportive of official diplomacy in order for the latter to reach its goals. Many diplomats, both Turkish and American, also made comments that prioritized the timing of official interactions, by stating that a political framework has to exist prior to the involvement of unofficial actors. Similar to the preferences put forth by Turkish diplomats in the selective group, some American diplomats think that track two diplomacy is good before or after an agreement, but not during the official negotiations (Chataway 1998: 276). In this regard, diplomats in both groups mentioned specific time periods in which unofficials are more helpful. Some American diplomats mentioned the contributions of unofficial actors in putting out fires or when relations have completely broken down (Chataway 1998: 276-277).

In sum, most of the similarities in the perceptions of Turkish and American diplomats with respect to track two diplomacy can be traced to the shared understandings of their common profession. Their common profession leads them to articulate similar concerns and shared perceptions about the contributions of track two diplomacy.

18) For American diplomats' views on this issue, see Ibid., p. 277. 


\section{Different Perceptions}

Some thoughts of Turkish diplomats on track two diplomacy were very different from the perceptions of the American diplomats. One striking difference is the argument put forth by Turkish diplomats that 'unofficial actors (are) manipulated and used by certain foreign states.' This view was not mentioned at all by any American diplomat in the research findings published by Chataway, despite the fact that they did not welcome unofficial diplomacy warmly with regard to the issues concerning the United States directly. ${ }^{19}$ Many Turkish diplomats across different groups showed skepticism towards foreign unofficial actors for various reasons, such as not being knowledgeable enough, trying to impose Eurocentric perspectives, and being manipulated and used by certain foreign states. Interestingly, diplomats who expressed such skeptical views came from many different departments ranging from the Middle East and Cyprus to the European and NATO bureaus of the Turkish Foreign Ministry.

Within this skeptical view, several Turkish diplomats, unlike American diplomats, stated that the historical traumas and the psychology of the people in the midst of deep-rooted conflicts in "our" region cannot be understood and dealt with by European "ethnocentric" values. Therefore, for the above mentioned reasons, many diplomats stated a preference for "local or regional unofficial actors" or for those who really know the characteristics of the region and the country. Otherwise, the efforts of foreign intermediaries may be titled as "biased," as articulated by many diplomats. This has important practical implications for organizations in the field especially in their efforts to establish collaborative efforts between the local-regional-international organizations. If international organizations collaborate with locally or regionally acclaimed and credible organizations, they are more likely to increase their influence on track one of the local governments. In countries like Turkey, where the history of foreign intervention by Western powers has a very negative connotation in the collective memory, collaboration of international organizations with respected local organizations can alleviate this suspicion and sensitivity.

Another significant point put forth by the Turkish diplomats, unlike American diplomats, was the notion of "consent", especially in reference to their experience with track two in Cyprus. Consent of the parties in conflict about who the third party will be and the recognition of the "equality" of each party in the unofficial meetings were considered as crucial by several diplomats. Thus, concern with equal treatment can be cited as another factor in the sensitivity zone alongside "impartiality" and "sincerity" of the unofficial actors.

Political culture, that is shaped as part of the political experience in a nation, is another dimension manifested in the perceptions of diplomats. There are differences among Turkish and American diplomats in this regard. For instance, the

\footnotetext{
19) For this specific concern, see Ibid., p. 275.
} 
debate over radical Islamists and the potential unofficial activities that may be carried out by these organizations was one of the primary concerns of the Turkish diplomats. ${ }^{20}$ In fact, for some diplomats this was a reason for viewing unofficial actors with suspicion. These diplomats expressed concerns about damage to the "secular regime" and the "image" of the country if such unofficial actors were allowed to engage in unofficial diplomatic activities as they pleased.

Another manifestation of different political cultures revealed itself in the statements of the diplomats concerning the historical experience with democratization and the incorporation of new ideas generated during the unofficial meetings at the political level. As some diplomats stated, the perception of track two in Turkey is closely related to the attitude towards civil society in the country. In the Turkish context, as mentioned earlier under the suspicious category, in one diplomat's words "most of the time such organizations are formed against the state." However, this attitude was not the case for any of the American diplomats.

In sum, differences reported between the two groups of diplomats can be attributed to several factors. These are issue sensitivities, country differences (size, power, service provider or not), and political culture (state-civil society relations). American diplomats, on the 'global service provider' end of this relationship, did not mention some of the issues addressed by Turkish diplomats, who are situated at the 'service receiving' end. In addition, most of the concerns expressed by Turkish diplomats were particular to the Turkish political context, as the Turkish diplomats themselves emphasized.

\section{Conclusion}

The number of track two initiatives has increased throughout the world in the last couple of decades with the expectation that track two would be useful and complementary to track one processes. However, despite a few empirical studies recently conducted on complementarity (e.g. Nan 2000), the idea that track two efforts are complementary to official negotiations and that official actors welcome these is still just an assumption held by many track two practitioners. In order to fortify this proposition, there is still a need for further empirical inquiry about when and how track two diplomacy is complementary to track one, and a need to know the actual perceptions of the official parties in these efforts. In addition, any attempt to understand the perceptions of track one actors should also include the track one actors of non-Western countries, as they are often the 'receivers' of track two initiatives. This study tries to remedy the second deficiency by presenting evidence from a survey of Turkish diplomats including their views of track two efforts and comparing these views to those of American diplomats.

\footnotetext{
20) It should be noted that these interviews were conducted before September 11, 2001. If American diplomats were to be interviewed today, they may express similar concerns as well.
} 
One important finding of this research that has implications for practice is that, similar to the track one diplomatic community in the US, the diplomatic community in Turkey is not homogenous. There is a spectrum of attitudes, ranging from very suspicious to very supportive, within track one. It is important for track two practitioners to know this attitudinal variation within track one, especially in order to develop appropriate 'insider strategies' aiming to work alongside track one. This article showed that within track one, certain types of diplomats are more willing to consider input from track two and that there are some sensitivities that diplomats of different countries agree on, due to their common profession. The article also showed that some concerns are idiosyncratic and unique to the diplomats of each country, due to national differences and because of location at either the 'receiving' or 'service providing' end. Of these sensitivities, some can easily be alleviated by the track two practitioners through trust building and better communication, such as the fear of track one diplomats about being taken over by track two. However, others are more difficult to alleviate, such as the deep suspicion among some Turkish diplomats about the legitimacy of track two actors.

Another finding of this article that has a theoretical implication is that it indicates a gap between the few empirical studies that exist on complementarity and the perceptions of some diplomats about what is useful and complementary to track one. Nan (2000: 332) found that "long term unofficial joint analysis in between negotiations" is highly complementary to track one negotiations. Despite this finding, there is no clear agreement among either the Turkish or the American diplomats with regard to the optimal timing of track two activities. While some diplomats see contemporaneous track two activities as useful, others see them as "meddling;" this latter group preferring sequential efforts instead. Future work in this area needs to address why the gap between the perceptions of the diplomats and the findings suggested by empirical work exists, by trying to better understand the motivations of diplomats, including those from countries not covered in this research.

Empirical work is deficient concerning some other issues that were raised by diplomats as well. For example, are track two and track one more complementary when they have compatible goals, when there is no violence, or when track two is held with certain types of actors, like business people, as suggested by some diplomats? Additional empirical work and further theory building are needed in this area that goes beyond a limited number of case studies.

\section{Acknowledgments}

This research was supported by a research grant from the Program on the Analysis and Resolution of Conflicts at Syracuse University. I especially thank Robert Rubinstein, James Bennett, and Mehmet Gürkaynak for their feedback during the conduct of this research and the writing of this paper. I also thank Richard 
Braungart, Louis Kriesberg, Ronald Fisher, the anonymous referee, and the panel members and audience at the 43rd Annual Conference of the International Studies Association in New Orleans for their comments on the earlier versions of this article. I am grateful to Refet Gürkaynak for his editorial comments.

\section{References}

Crocker, Chester, F. O. Hampson, P. Aall (1999) Herding Cats: Multiparty Mediation in a Complex World. Washington DC: United States Institute of Peace Press.

Chataway, Cynthia. (1998). “Track II Diplomacy: From a Track I Perspective.” Negotiation Journal, July: 269-285.

— (1999). "The Evolution of Diplomacy: Coordinating Tracks I and II," in D.A. Walter, editor, World Order for a New Millennium: Political, Cultural and Spiritual Approaches to Building Peace. New York: St. Martin's Press.

Cuhadar, Esra C. (2004) Evaluating Track Two Diplomacy in Pre-Negotiation: A Comparative Assessment of Track Two Initiatives on Water and Jerusalem in the Israeli-Palestinian Conflict. Ph.D. Dissertation. Syracuse University.

Diamond, Louise and John McDonald. (1996). Multi-Track Diplomacy: A Systems Approach. 3rd edition. West Hartford, CT: Kumarian Press.

Fisher, Ronald. (1997). Interactive Conflict Resolution. Syracuse: Syracuse University Press.

Fitzduff, Mari and Cheyanne Church. (2004) "Stepping up to the Table: NGO Strategies for Influencing Policy on conflict Issues," in Mari Fitzduff and Cheyanne Church, editors, NGOs at the Table: Strategies for Influencing Policies in Areas of Conflict. Lanham: Rowman and Littlefield.

Keashly, Loraleigh, and Ronald Fisher. (1996). "A Contingency Perspective on Conflict Interventions: Theoretical and Practical Considerations," in Jacob Bercovitch, editor, Resolving International Conflicts: The Theory and Practice of Mediation. Boulder: Lynne Rienner Publishers.

Kelman Herbert. (1995). "Contributions of an Unofficial Conflict Resolution Effort to the IsraeliPalestinian Breakthrough.” Negotiation Journal 11: 19-28.

Kriesberg, Louis. (1996). "Coordinating Intermediary Peace Efforts." Negotiation Journal, October: 341-352.

Lewis, Bernard. (2002). What Went Wrong. New York: Oxford University Press.

Mardin, Serif. (1995). "Civil Society and Islam," in John Hall, editor, Civil Society: Theory, History, Comparison. Cambridge: Polity.

McDonald, John. (1991)."Further Exploration of Track Two Diplomacy," in Louis Kriesberg and Stuart Thorson, editors, Timing the De-escalation of International Conflicts. Syracuse: Syracuse University Press.

Mitchell Christopher. 1993. "Problem-solving Exercises and Theories of Conflict Resolution," in Dennis Sandole and Hugo van der Merwe, editors, Conflict Resolution: Theory and Practice. Manchester: Manchester University Press.

Montville, Joseph. (1987). "The Arrow and the Olive Branch: A Case for Track Two Diplomacy," in John McDonald and D. Bendahmane, editors, Conflict Resolution: Track Two Diplomacy, Washington, DC: Foreign Service Institute, US Department of State.

Nan, Susan Allen (2000) Complementarity and Coordination of Conflict Resolution Efforts in the Conflicts over Abkhazia, South Ossetia, and Transdniestria. Ph.D. Dissertation, Institute for Conflict Analysis and Resolution, George Mason University, Fairfax, VA.

Saunders, Harold H. (1999). A Public Peace Process. New York: St. Martin's Press.

Volkan, Vamik. (1991). "Official and Unofficial Diplomacy: An Overview," in Vamik Volkan, J. Montville, and D. Julius, editors, The Psychodynamics of International Relationships: Unofficial Diplomacy at Work, vol. 2. Lexington: Lexington Books. 